\title{
Effect of Eight Weeks of Aerobic Training and Green Tea Supplementation on Cardiovascular Risk Factors in Inactive Overweight Women
}

\author{
Fathei M.* PhD, Khairabadi S. ${ }^{1} P h D$, Ramezani F. ${ }^{2} M S c$, Hejazi K. ${ }^{1} P h D$
}

*Sport Physiology Department, Sports Sciences Faculty, Ferdowsi University of Mashhad, Mashhad, Iran 1 Sport Physiology Department, Sports Sciences Faculty, Ferdowsi University of Mashhad, Mashhad, Iran

${ }^{2}$ Sport Physiology Department, Sports Sciences Faculty, Shahid Beheshti Teacher Training College, Mashhad, Iran

\begin{abstract}
Aims: Physical activities, as well as diet, are known as the truest scientific methods to reduce the signs of the cardio-vascular diseases. The aim of this study was to investigate the effects of 8-week aerobic trainings and green tea supplementation on some of the cardio-vascular risk factors in the obese inactive women.

Materials \& Methods: In the semi-experimental study, 40 obese inactive women, who were residents of Mashhad Township, were studied in 2015. The subjects, selected via purposeful available sampling method, were randomly divided into 4 groups ( $n=10$ per group). The groups were green tea, aerobic training, aerobic training and green tea supplementation, and control groups. 8week training program consisted of three 45- to 60-minute sessions per week. Green tea was consumed by green tea group three times a day after each meal. The composed group underwent both interventions, while control group underwent no intervention. Data was analyzed by SPSS 15 software using correlated T test and one-way ANOVA.

Findings: Mean total cholesterol level was significantly changed in green tea, aerobic training, and composed groups in the posttest stage compared to the pretest stage $(\mathrm{p}<0.05)$. Mean triglyceride level was significantly changed in green tea and aerobic training groups in the posttest stage compared to the pretest stage $(\mathrm{p}<0.05)$. Mean low density lipoprotein was significantly changed in green tea and composed groups in the posttest stage compared to the pretest stage $(\mathrm{p}<0.05)$. Mean high-density lipoprotein was significantly changed only in aerobic group in posttest stage compared to the pretest stage $(\mathrm{p}<0.05)$. In addition, mean concentration of $\mathrm{C}$-reactive protein was significantly reduced in aerobic training $(\mathrm{p}=0.01)$ and composed $(\mathrm{p}=0.04)$ groups.

Conclusion: 8 weeks aerobic training, green tea consumption, and their composition reduce the cardiovascular risk factors in inactive obese women in a relatively similar manner.
\end{abstract}

\section{Keywords}

Aerobic Exercise [https://www.ncbi.nlm.nih.gov/mesh/68015444];

Green Tea [https://www.ncbi.nlm.nih.gov/mesh/68013662];

Cardiovascular Abnormalities [https://www.ncbi.nlm.nih.gov/mesh/68018376]

\footnotetext{
*Corresponding Author

Tel: +98 (51) 18833910

Fax: +98 (51) 18829580

Address: Faculty of Physical Education and Sport Sciences, Ferdowsi University of Mashhad, Paradise Daneshgah, Azadi Square, Mashhad, Iran. Post Code: 91779-48979

dr.mfathei@gmail.com

Received: October 16, 2015 Accepted: May 10, 2016 ePublished: October 1, 2016
} 
مقدمه

در حال حاضر خاقى و اضافهوزن در جهان رو به افزايش است و اين موضوع تنها منحصر به كشورهاى توسعهيافته نيست [1,2]. كاهش يا افزايش وزن كاهى از برهمخوردن تعادل انرزى ناشى مى نى بهود و اين

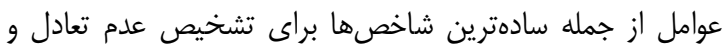
تنظيم انرزى در بلن بلهساب مىآيند. ايجاد تغيير در روند تعلي تعادل

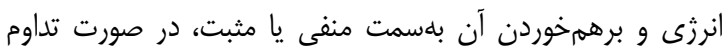

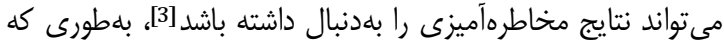
مصرف بيش از حد جربىها زمينهساز ابتلا به بيمارىهاى مزمن مانند ديابت، بيمارىهاى قلبى - عروقى و برخى از انواع سرطانها

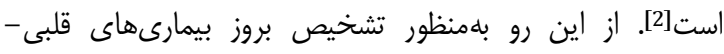
عروقى، عوامل خطرزاى جديدى همجون هموسيستئين و پروتئين واكنشگرC C كشف شدهاند كه قوىتر از عوامل خطرزاى (CRP) كلاسيك بوده و بلهور مستقل مىتوانند خطر ابتلا به بيمارىهاى قلبى - عروقى را نشان دهند [4].

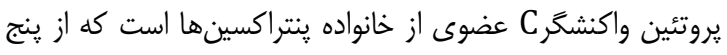
زيرواحد سبكيلودالتونى تشكيل شده است و از كبد و و اندوتليوم سرخرگهاى كرونرى مشتق مىشود. اين يروتئين از طريق افزايش

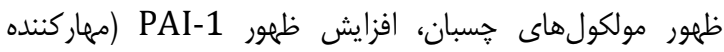

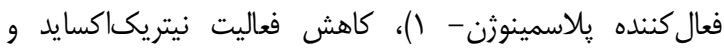

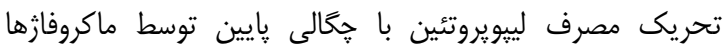

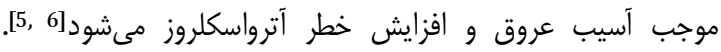
براساس مطالعات صورت گرفته، مقادير يروتئين واكنشگر C در زنان

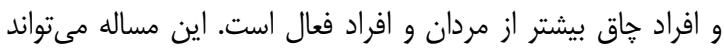
بهلت ميزان بافت هربى در زنان باشد كه نسبت به مردان بيشتر است و مىتواند زنان را براى ابتلا به التهاب مزمن مستعدتر كند بـان. از اين رو يكى از روشهاى كاهش سطوح التهاب در بدن، شركت در فعاليتهاى بدنى منظم و رزيمهاى غذايى سالم است كه نتايج برخى از تحقيقات نشان مى دهد شركت منظهم در برنامههاى ورزشى

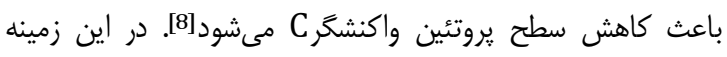

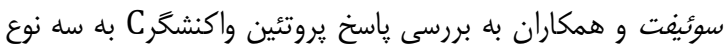

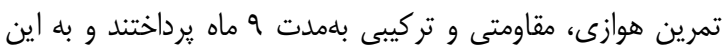

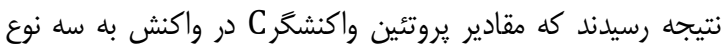
تمرين كاهش معنى دارى بيدا نكرد [9]. يكى ديخر از روشهاى افزايش اثرات ضدالتهابى و كاهش بروز

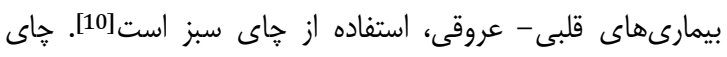

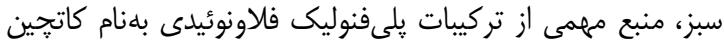

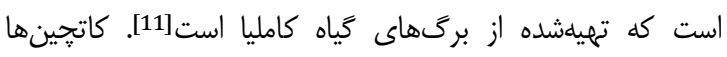
اصلىترين فلاونهاى خاى سبز هستند كه r تا ع ساعت يس از

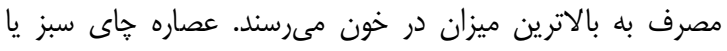

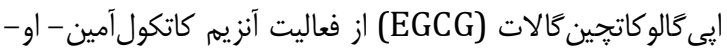
متيلترانسفراز (COMT) كه كاهشدهنده نورآدرنالين است،
تاثير هشت هفته تمرين هوازى و مكماردمل جانى سبز بر برخى عوامل خطر قلبى - عروقى زنان جاق غير فعال

PhD مهرداد فتحىى

كروه تربيت بدنى، دانشكده علوم ورزشى، دانشكاه فردوسى مشهل، مشهر، ايران

سميه خيرآبادى PhD

كروه تربيت بدنى، دانشكده علوم ورزشى، دانشكاه فردوسى مشهله، مشهر، ايران

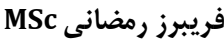

كروه تربيت بدنى، دانشكده علوم ورزشى، دانشخاه تربيت معلم شهيد بهشتى، مشهل، ايران

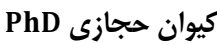

كروه تربيت بدنى، دانشكده علوم ورزشى، دانشكاه فردوسى مشهل، مشهد، ايران

جكيده

اهداف: فعاليت بدنى و رثيم غذايى بهعنوان اصولىترين و علمىترين روشهاى كاهش علايم بيمارىهاى قلبى - عروقى شناخته شدهاند. هدف

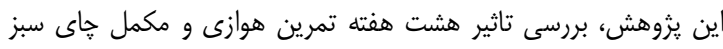

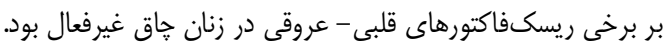

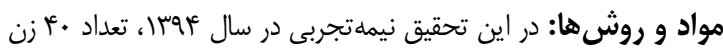

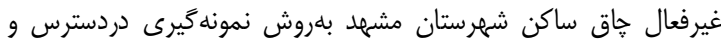

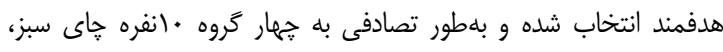

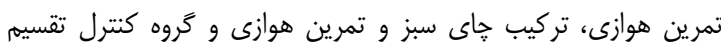

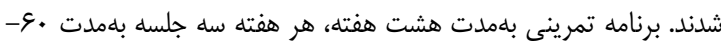

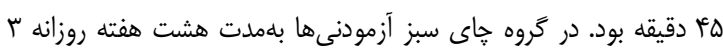

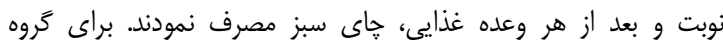

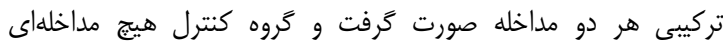

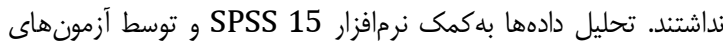

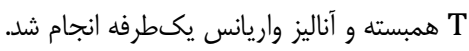
يافتهها: ميانگين سطوح كلسترول تام در گروه خاى سبز، تمرين هوازى

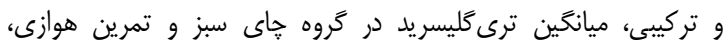

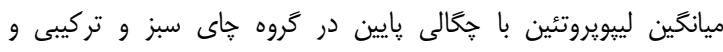

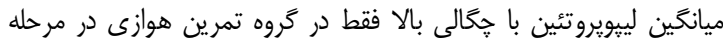

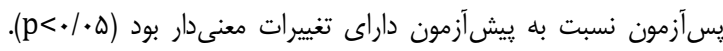

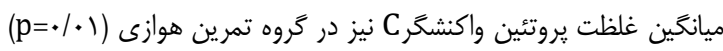

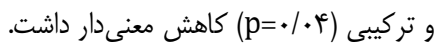

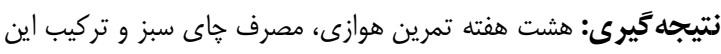

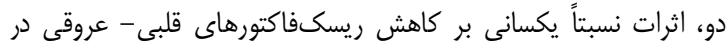
زنان خاق غيرفعال دارد. كليدوازهها: تمرين هوازى، خاى سبز، ريسكان دارد

تاريخ دريافت: - (تاريخ

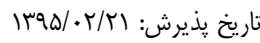

"نويسنده مسئول: dr.mfathei@gmail.com

دوره זr، شماره ז، باييز هوها

فصلنامه افق دانش 


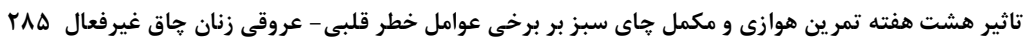

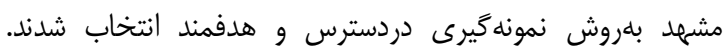

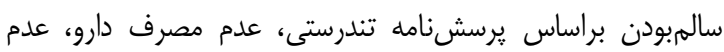

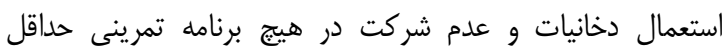

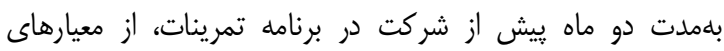

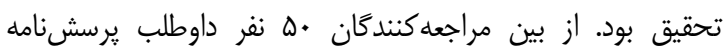

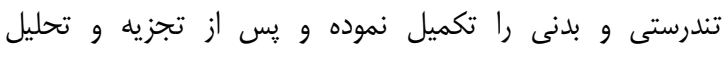

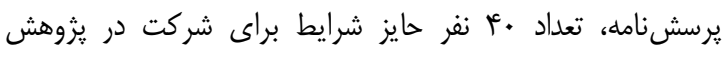

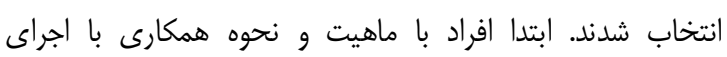

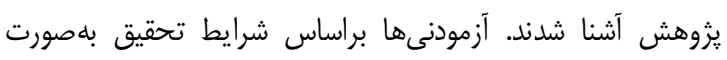
داوطلبانه در تحقيق شركت كرده و فرم رضايتنامه را امضا نمودند.

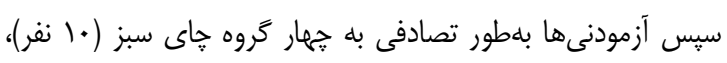

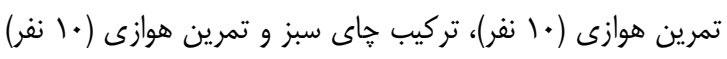

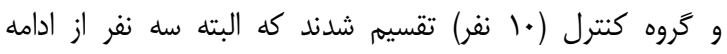
شركت در جلسات تمرين يا پسآزمون به دلايل شخصى بـ بازماندند. براى ارزيابى تركيبات بدن به ترتيب طول قد آزمودنىها با قدسنج

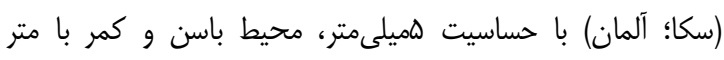

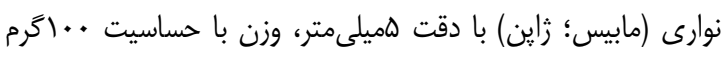

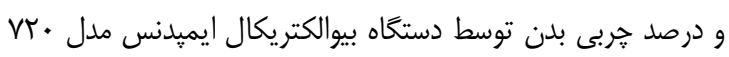
مجل (In body) مجذور قد به متر، نمايه توده بلن بر حسب كيلوگرم بر متر مربع

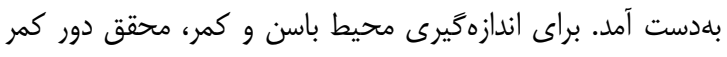
آزمودنىها را با يك متر نوارى در كمترين نقطه (بين انتهاى يايينى قفسه سينه و ناف) بر حسب سانتىمتر و دور باسن (در عريضت دئرين

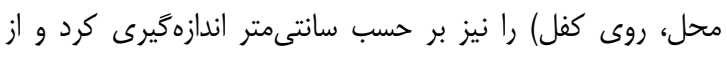

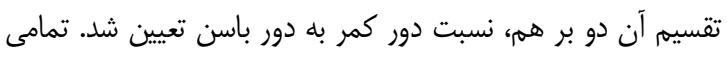

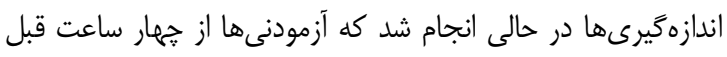

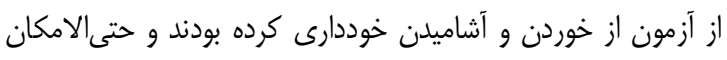

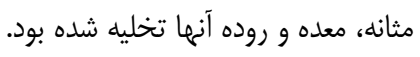
در دو وهله نمونههاى خونى از سياهرگ دست جِ

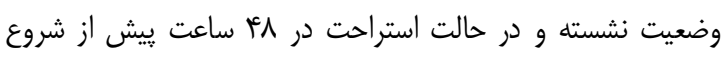

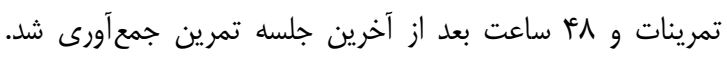

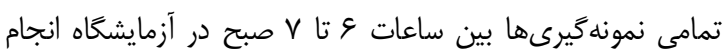

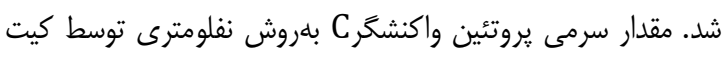

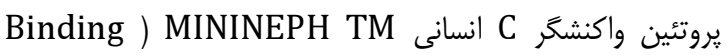
Site

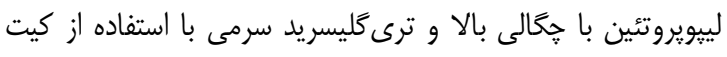

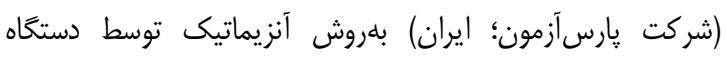

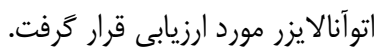
برنامه تمرينى بلممدت هشت هفته (سه جلسه در هفته و هر جلسه

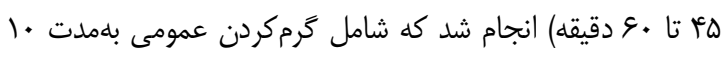

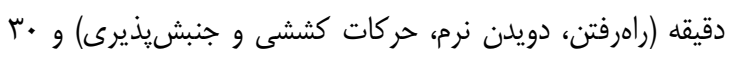

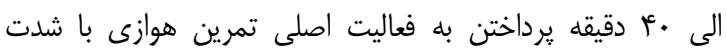

جلوگيرى مى كند و با اثر تنظيم كنندگى بر فعاليت سمياتيك و

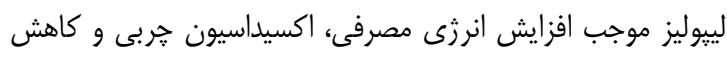
توده جربى بدن مىشود. كاهش وزن ناشى از مصرف خاى سبر سبز

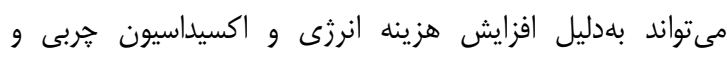

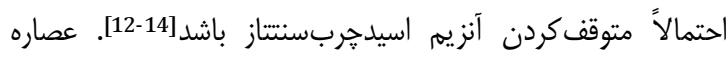

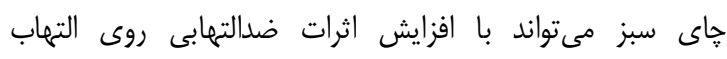
سيستميك خفيف باعث كاهش سطح يروتئين واكنشخر C شود[15].

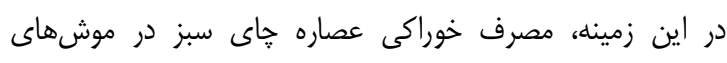

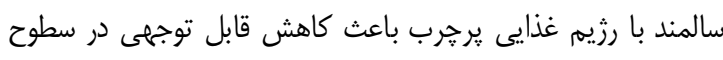

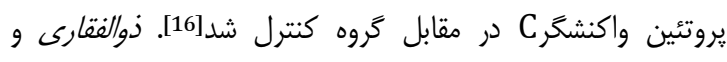
همكاران با مقايسه تاثير سه روش مصرف عصاره جاى ستى سبز،

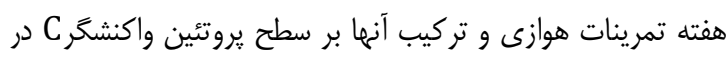

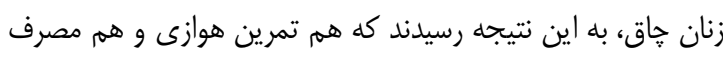

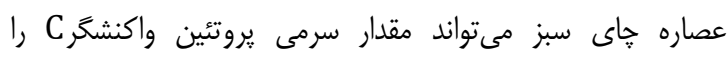

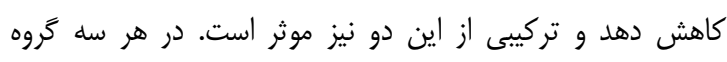

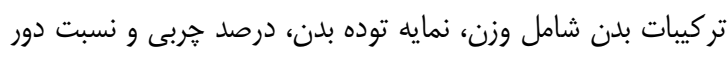
كمر به باسن كاهش معنىدارى نداشت، اما دور كمر در گروه تمرين

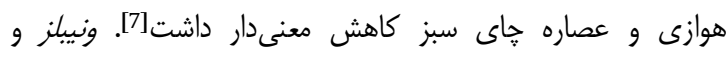
همكاران نشان دادند كه مصرف عصاره جاى هبى سبز همراه با تمرين

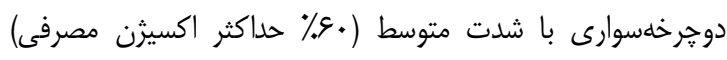
موجب افزايش سهم جربى در هزينه انرزى تام مىشود[17].

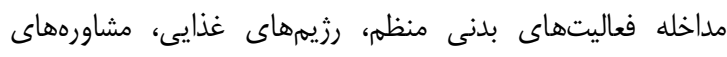

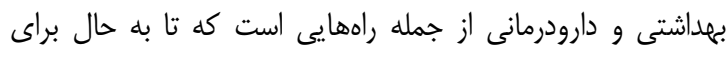

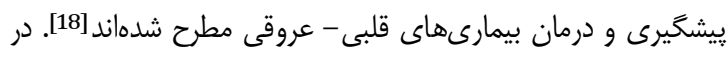

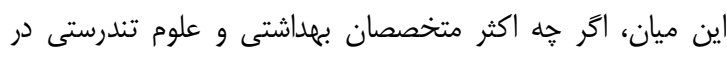

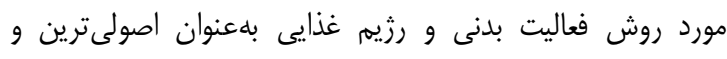
علمىترين روش كاهش علايهم بيمارىهاى قلبى - عروقى اتفاق

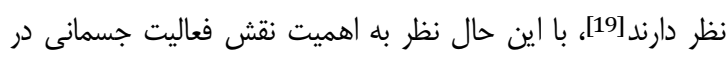

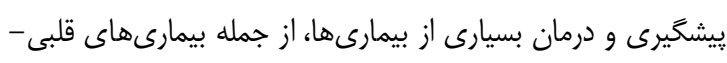

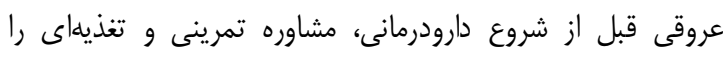

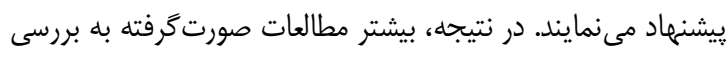

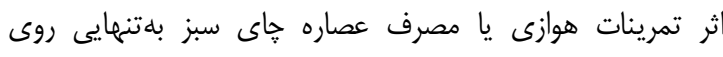

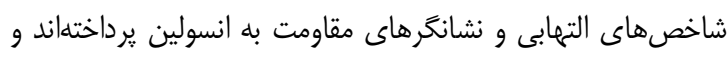
با توجه به بررسىهاى انجامشده مطالعات اندكى اثر تركيب اين دو روش را بر سطح اين شاخصها مورد بررسى قرار دادهاند.

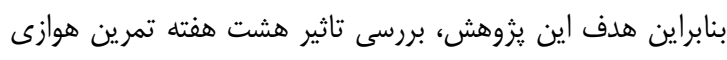

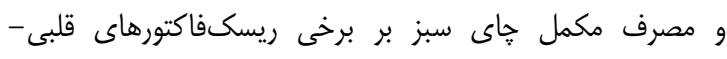

عروقى در زنان خاق غيرفعال بود.

\section{مواد و روشها}

در اين تحقيق نيمهتجربى با طرح ييش آزمون و يسآزمون با گروها

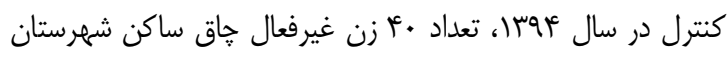


تغييرات درونَروهى و از آناليز واريانس يكىطرفه (آنووا) براى مقايسه تغييرات واريانس بين زَروهى استفاده شد.

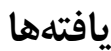

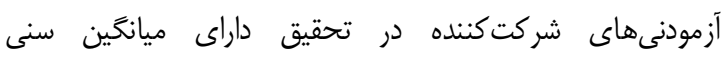

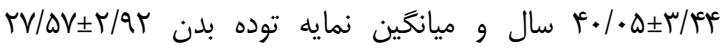

كيلوگرم بر متر مربع بودند (جدول () ميانين نمايه

جدول () مشخصات جمعيتشناختى آزمودنىهاى شركت كننده در تحقيق

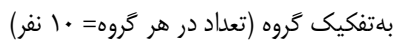

\begin{tabular}{|c|c|c|c|}
\hline 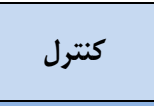 & تمرين هواى سبز و & تموازين & 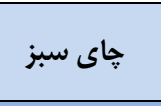 \\
\hline $\mid r / / F \cdot \pm r / F)$ & $r \cdot / \cdot \pm r / 4 r$ & $r r / r \cdot \pm r / 19$ & سن (سال) \\
\hline $10 T / T \cdot \pm V / T r$ & $\mid Q F / \cdot \cdot \pm F / \Delta S$ & $1 Q \Delta / \Lambda \cdot \pm F / V V$ & 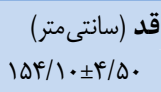 \\
\hline$\varepsilon V / T \cdot \pm F / q g$ & $\Delta Q / V \cdot \pm \Delta / T r$ & $\varepsilon V / \mu q_{ \pm} r / \cdot r$ & وزن (كيلوكرم) هبهام \\
\hline$r q / I V \pm r / \mu r$ & \multicolumn{3}{|c|}{ تمايه توده بدن (كيلوكرم بر متر مربع) } \\
\hline
\end{tabular}

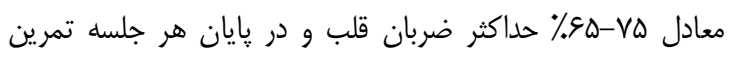

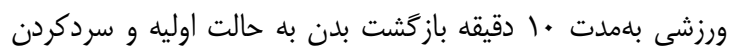

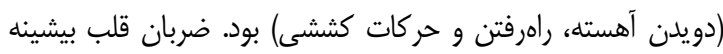

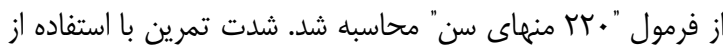

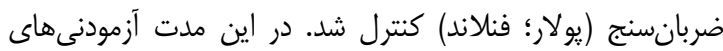

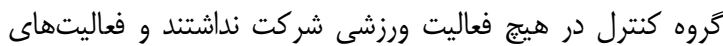

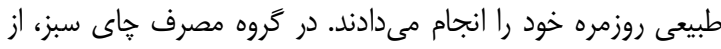

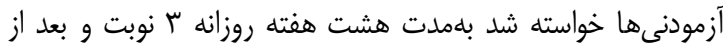

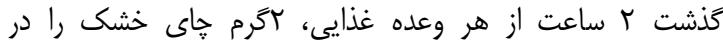

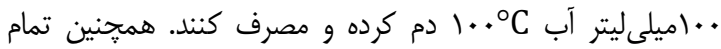
آزمودنىها از يك نوع خاى سبز استفاده مىنمودند. خاى مصرفى إنى

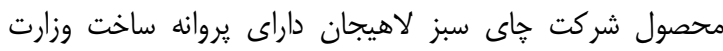

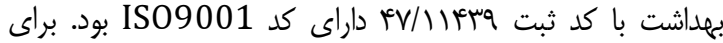
كروه تركيبى تمرين و مكمل خاى سبز هر دو مداخله كرفت.

SPSS 15 در קايان، دادههاى جمع آورىشده با كمى نرمافزار

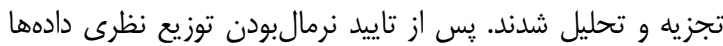

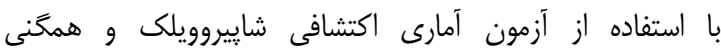
واريانسها توسط آزمون لون، از آزمون T همبسته براى مقايسه

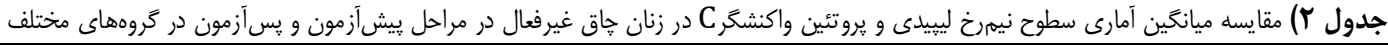

\begin{tabular}{|c|c|c|c|c|}
\hline سطح معنى دارى & تروه كنترل & تحروه جاى سبز و هوازى & كروه تمرين هوازى & كروه جاى سبز \\
\hline .1 .11 & $\begin{array}{c}\mid A T / \Lambda \cdot \pm \& / T \Delta \\
\mid \Lambda F / Q \cdot \pm \Delta / \& T \\
\cdot / T V E\end{array}$ & $\begin{array}{c}1 \Lambda r / r \cdot \pm r / v q \\
M \cdot / r \cdot \pm r / q r \\
/ . \cdot 1\end{array}$ & $\begin{array}{c}\mid \Lambda \tau / \Lambda \cdot \pm \Delta / \Psi \\
\mid \Lambda \cdot / \cdot \pm \Delta / \Delta q \\
\cdot / \cdot \cdot 1\end{array}$ & 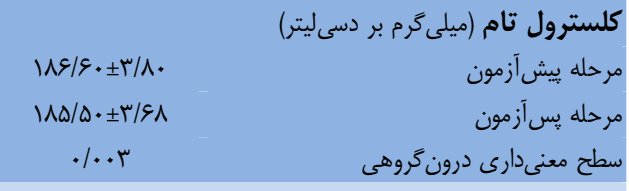 \\
\hline.$/ . .1$ & $\begin{array}{c}\mid 01 / 4 \cdot \pm V / \cdot 1 \\
|0| / 9 \cdot \pm 8 / 10 \\
\cdot / 98\end{array}$ & 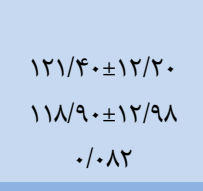 & $\begin{array}{c}|r Q / T \cdot \pm| r / T E \\
|r \cdot / \Delta \cdot \pm| r / F \Delta\end{array}$ & 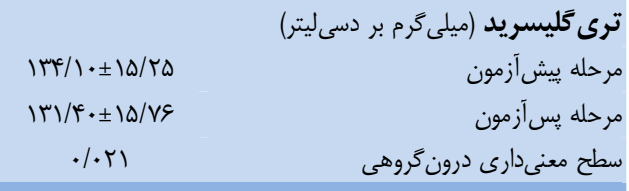 \\
\hline$\cdot / 4 \wedge 1$ & 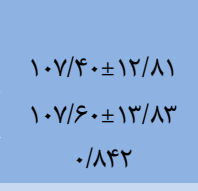 & $\begin{array}{c}1 \cdot N / 1 \cdot \pm|r / 4| \\
\begin{array}{c}1 \cdot \Delta / r \cdot \pm \mid r / \Delta r \\
\end{array}\end{array}$ & $\begin{array}{c}1 \cdot r / V \cdot \pm|\Delta / T| \\
Q N / \Delta \cdot \pm|V /| 19 \\
\cdot / \cdot 1 \cdot\end{array}$ & 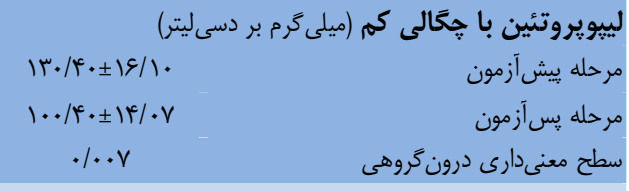 \\
\hline ./VED & $\begin{array}{c}\Delta Y / T \cdot \pm F / K \varepsilon \\
\Delta) / \cdot \cdot \pm \varepsilon / \& q \\
\cdot / r V q\end{array}$ & $\begin{array}{c}\Delta \cdot / \Delta \cdot \pm q / T F \\
\Delta r / T \cdot \pm \varepsilon / 1 . \\
\cdot / / 9 T\end{array}$ & $\begin{array}{c}\qquad N / \mu \cdot \pm N / I V \\
0 \cdot / \cdots \pm N / \cdot \Delta \\
\cdot / \cdot 1\end{array}$ & 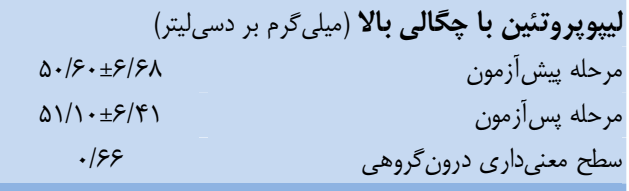 \\
\hline .1 .9 & 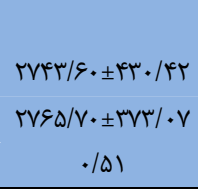 & 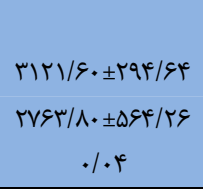 & 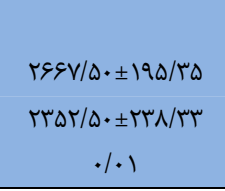 & 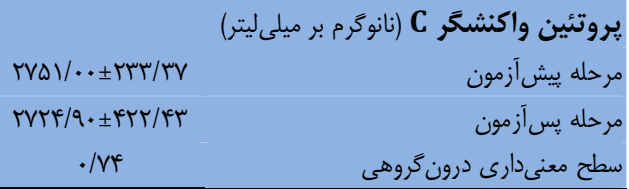 \\
\hline
\end{tabular}




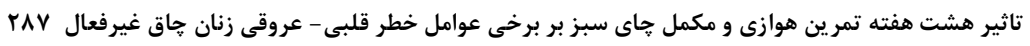

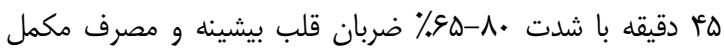

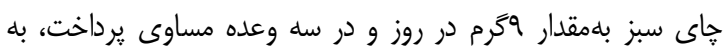

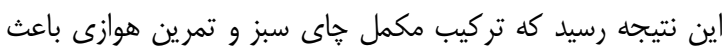

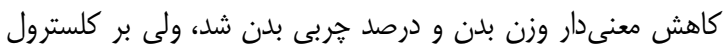

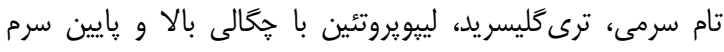
تاثير معنى دارى نداشت[21]. تمرينات هوازى را مىتوان بلهعنوان روشى موثر براى تغييرات در لراسير

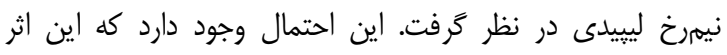

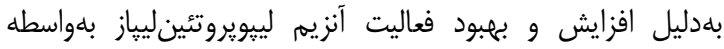

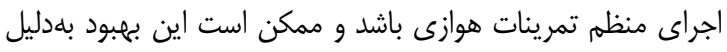

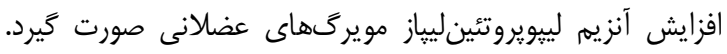
همجنين عنوان شده است كه إيىنفرين موجب اين افزايش مى إشود

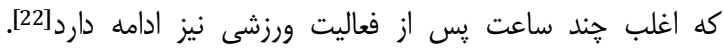

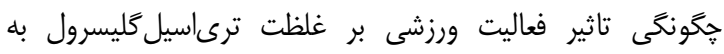
غلظت قبل از فعاليت نيز بستخى دارد و در افرادى كه داراى مقادير

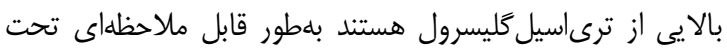
اجراى تمرينات ورزشى كاهش مىيابد[23]. اجراى تمرينات ورزشى لئى سبب افزايش ليبوليز و كاهش اسيدهاى خرب در خون و عضلات مىشود. اين موضوع بلنوبهخود قشر مازاد جربى (كلسترول آزاد و

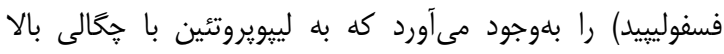
منتقل شده و سبب افزايش آن مىشود. علت احتمالى ديخر افزايش

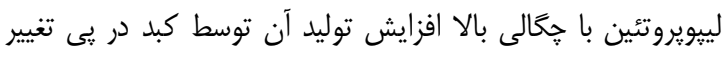

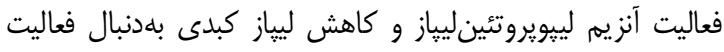

بدنى است] [24].

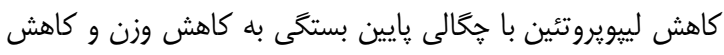

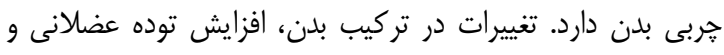

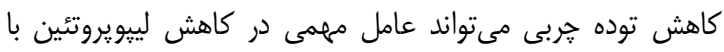

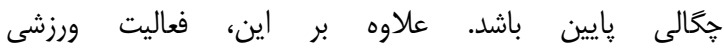
ليستين كلسترولاسيلترانسفراز را فعال كرده و سبب تغذيه ذراتئ

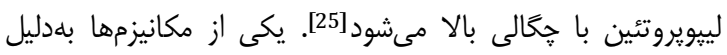

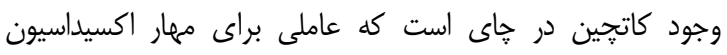

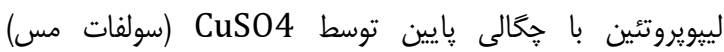
است[26] و همجنين بلهواسطه تاثير بر آنزيمهاى محدودكنتده بيوسنتز كلسترول، سبب مهار كلسترول مىشود[27]. مكانيزم

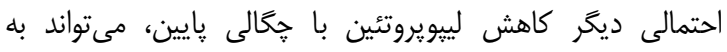

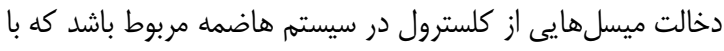

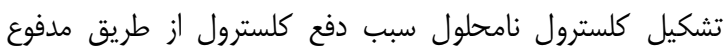
مىشود و عاملى براى كاهش جذب كلسترول است. كاهش جذب كاب

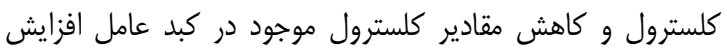

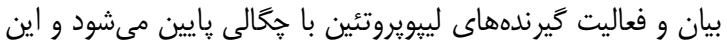

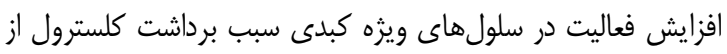

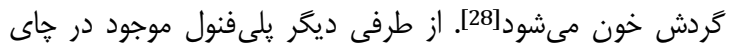

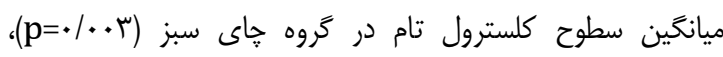

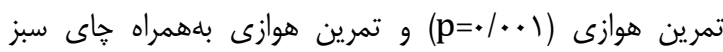

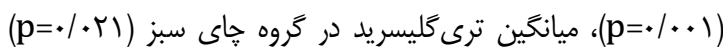

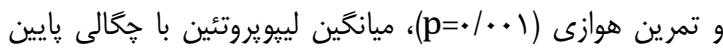

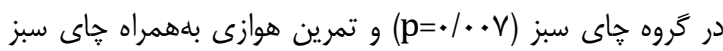

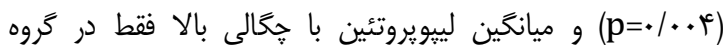

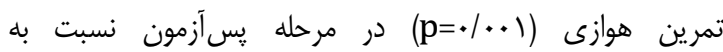

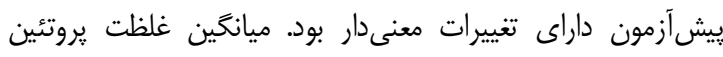

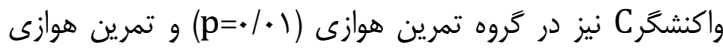

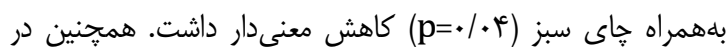

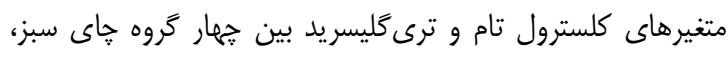

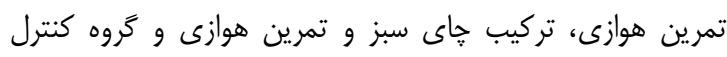

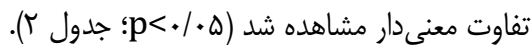

\section{بحث}

هدف از مطالعه حاضر، بررسى تاثير هشت هفته تمرين هوازى و مكمل هاى سبز بر برخى ريسكفاكتورهاى قلبى - عروقى زنان

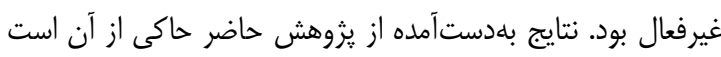
كه تغييرات سطوح نيمرخ ليييدى همجون مقادير كلسترول تام درد

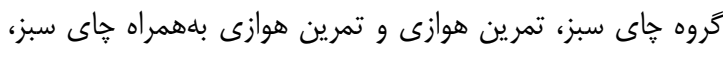

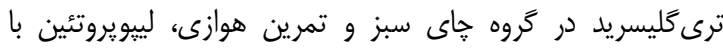

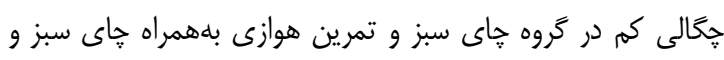

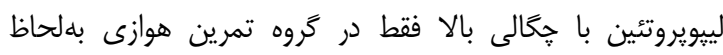

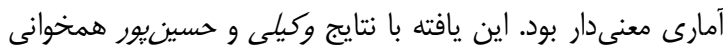

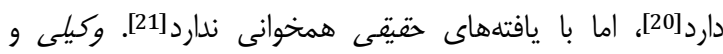

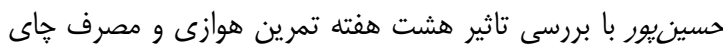
سبز بر برخى عوامل خطرزاى قلبى- عروقى زنان خاق به اين

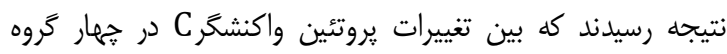

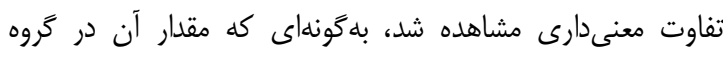

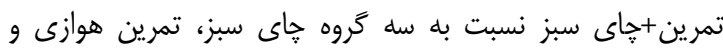

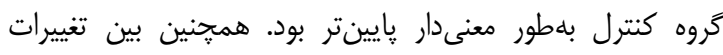

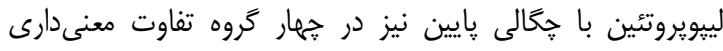

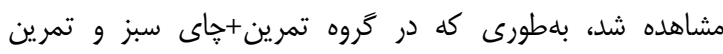

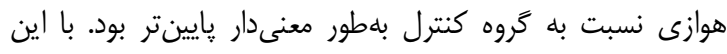

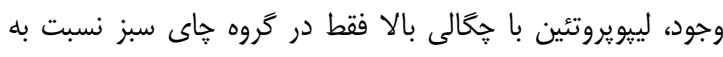

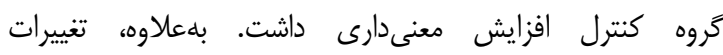
ترى گليسريد در جههار گروه تفاوت معنى دارى نداشت، اما درصد קربى زيريوستى در هر سه گروه تجربى بلهطور معنى دار كاهش

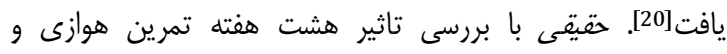

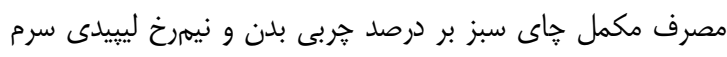

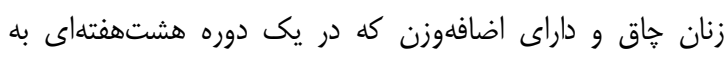
اجراى تمرينات هوازى شامل سه جلسه در هفته، هر جلسه بلهمدت 
نتايج متضاد احتمالاً ناشى از اختلاف در شرايط فيزيولوزيك افراد

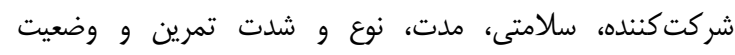

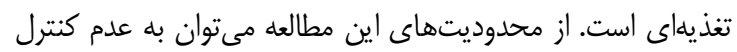

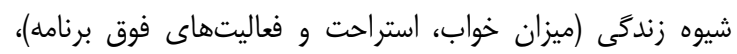

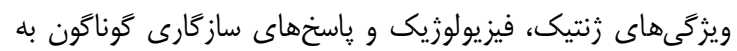

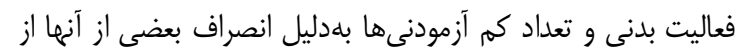

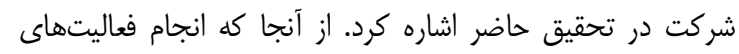

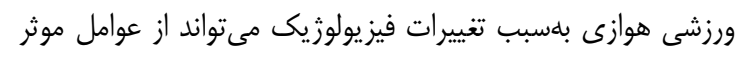

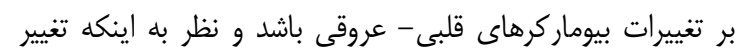

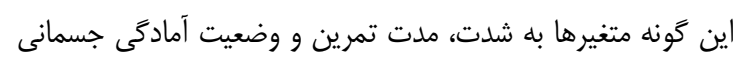

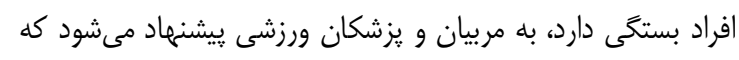

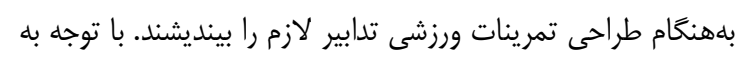

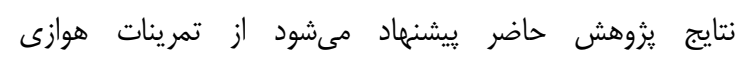

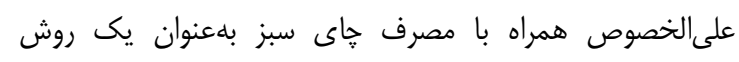

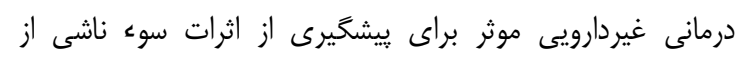
افزايش بروز بيمارى آترواسكلروزيس استفاده شود.

\section{نتيجه كَيرى}

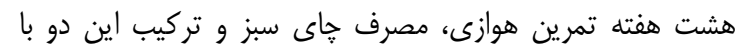

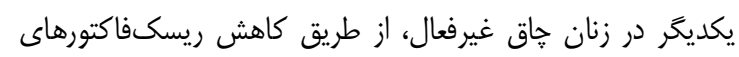

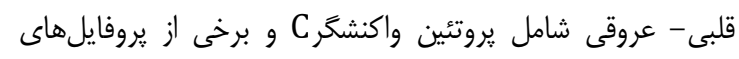

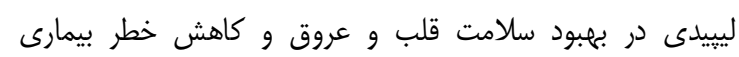
آترواسكلروز موثر است.

تشكر و قدردانى: بدين وسيله از زحمات بىدريغ آزمودنىهاى

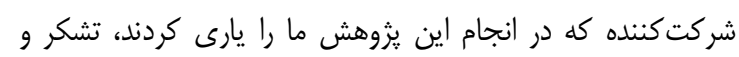
قدردانى مىنماييمه.

تاييديه اخلاقىى: آزمودنىها براساس شرايط تحقيق بهصورت

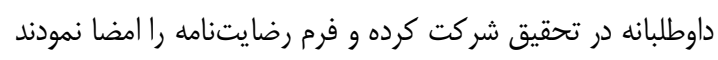
تعارض منافع: موردى توسط نويسندكان كزارش نشده است

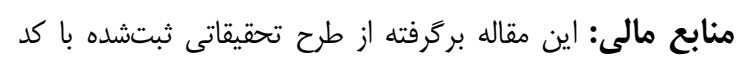

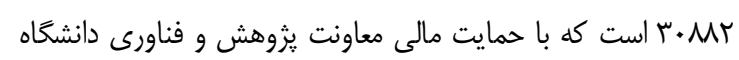
فردوسى مشهر انجام شده است.

منابع

1- Khalilzadeh M, Azali Alamdari K, Choobineh S, Ebadi Shirmard B, Ghahramani M.Effects of aerobic training with low and intermediate intensity on appetite, body weight, exercise energy expenditure and plasma ghrelin level in relatively thin and obese sedentary women. Iran J Nutr Sci Food Technol. 2011;6(1):1-10. [Persian] 2- Atashak S, Azarbayjani MA, Sharafi H. Effect of threemonth progressive resistance training on leptin and Interleukin-6 concentration in obese men. Pajoohandeh.
سبز با مهار اكسيداسيون ليبويروتئين با خيكالى بإيين، افزايش

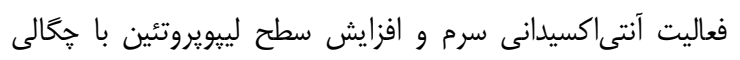

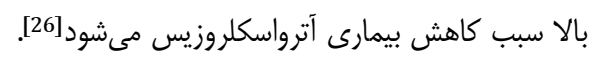

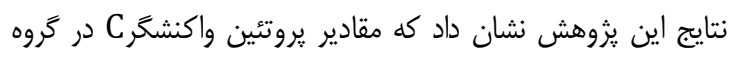

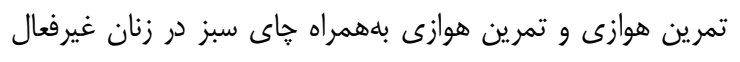

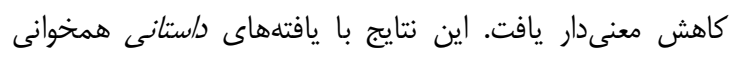

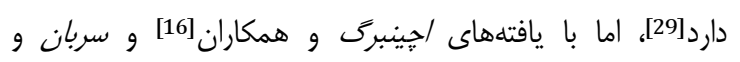

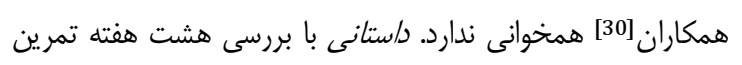

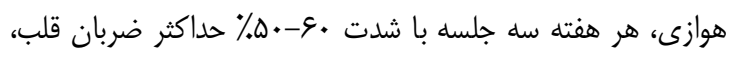

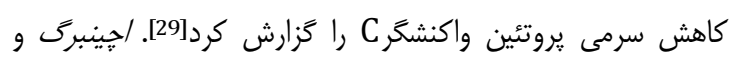

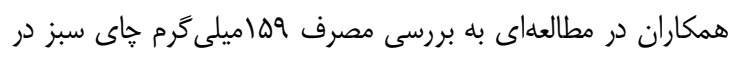

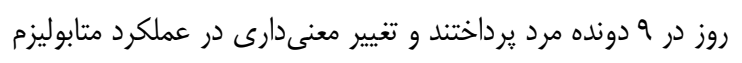

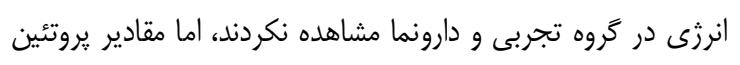

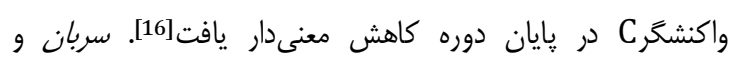

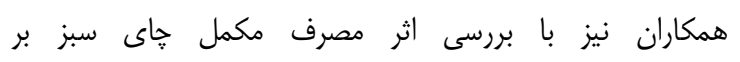

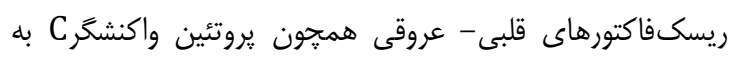

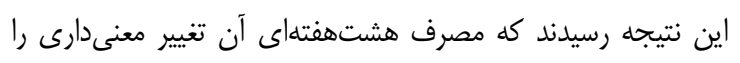
در سطوح بروتئين واكنشكر C بلوجود نمى آورد [30].

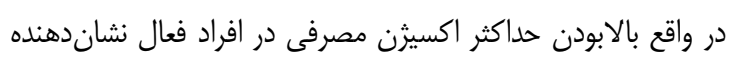

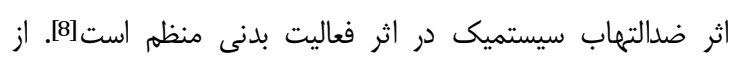

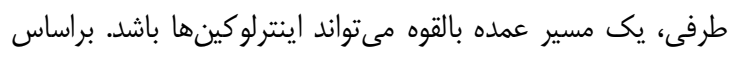

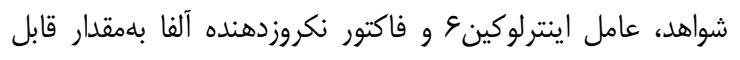

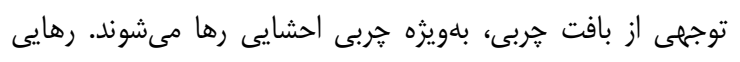

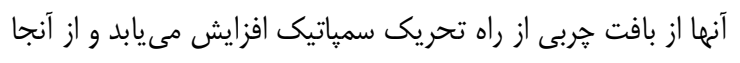

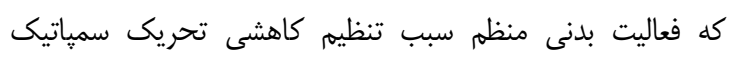

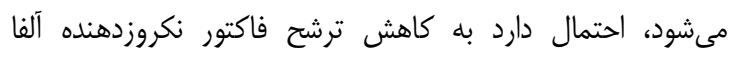

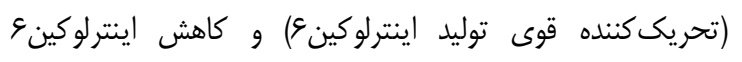

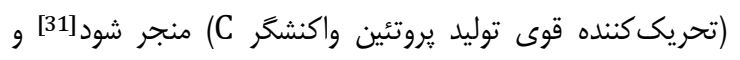

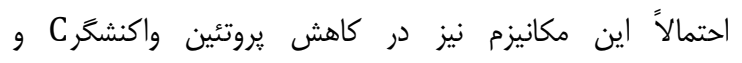

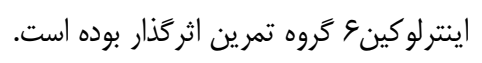

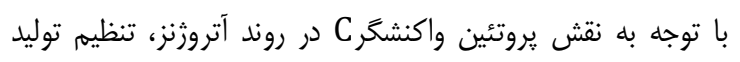

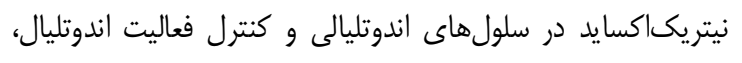

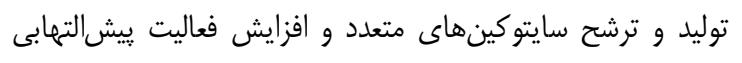

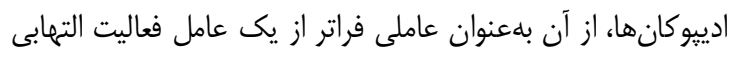

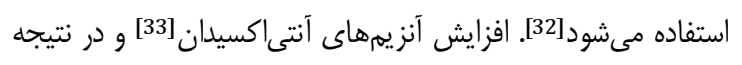

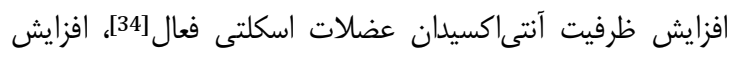

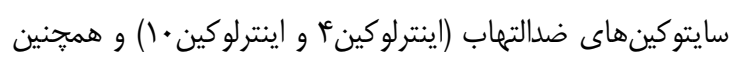

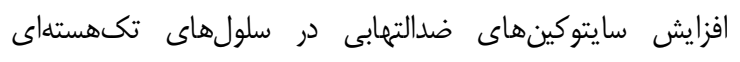

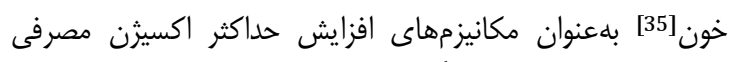

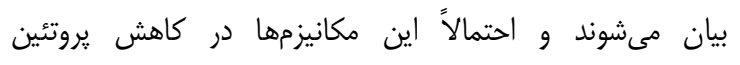
واكنشكر C عروه تمر ينى موثر بودهاند. 


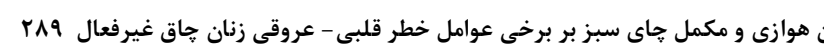
cohort, and intervention studies. Circ. 2002;105(7):8938.

20- Vakili J, Hosseinpour L. The effects of 8 weeks aerobic exercise training along with green tea consumption on the cardiovascular risk factors in obese women. J Pract Stud Biosci Sport. 2015;3(5):78-88. [Persian]

21- Haghighi AH, Yaghoubi M, Hosseini Kakhk SA. The effect of eight weeks aerobic training and green tea supplementation on body fat percentage and serum lipid profiles in obese and overweight women. Med J Mashhad Univ Med Sci. 2013;56(4):211-18. [Persian]

22- Lambers S, Van Laethem C, Van Acker K, Calders P. Influence of combined exercise training on indices of obesity, diabetes and cardiovascular risk in type 2 diabetes patients. Clin Rehabil. 2008;22(6):483-92.

23- van Loon LJ. Use of intramuscular triacylglycerol as a substrate source during exercise in humans. J Appl Physiol. 2004;97(4):1170-87.

24- Rahimi, N., S.M. Marandi, and M. Kargarfard, The effect of eight weeks aquatic training on lipid profile of patients who suffer from type ii diabetes. J Isfahan Med Sch. 2011;29(148): 988-96. [Persian]

25- Cauza E, Hanusch-Enserer U, Strasser B, Ludvik B, Metz-Schimmerl S, Pacini G, et al. The relative benefits of endurance and strength training on the metabolic factors and muscle function of people with type 2 diabetes mellitus. Arch Phys Med Rehabil. 2005;86(8):152 7-33.

26- Cabrera C, Artacho R, Giménez R. Beneficial effects of green tea: A review. J Am Coll Nutr. 2006;25(2):79-99.

27- Abe I, Seki T, Umehara K, Miyase T, Noguchi H, Sakakibara J, et al. Green tea polyphenols: Novel and potent inhibitors of squalene epoxidase. Biochem Biophys Res Commun. 2000;268(3):767-71.

28- Bursill CA, Roach PD. A green tea catechin extract upregulates the hepatic low-density lipoprotein receptor in rats. Lipids. 2007;42(7):621-7.

29- Dastani M, Rashid Lamir A, Rashid Lamir Sh, Saadatnia A, Ebrahimnia M. The effect of eight weeks of aerobic training on hsCRP and resistin levels in menopause women. Eur J Experiment Biol. 2013;3(4):43-7.

30- Serban C, Sahebkar A, Antal D, Ursoniu S, Banach M. Effects of supplementation with green tea catechins on plasma C-reactive protein concentrations: A systematic review and meta-analysis of randomized controlled trials. Nutr. 2015;31(9):1061-71.

31- Christopherson J, Sumer V, Kirkendal D, Jones M. Effects of exercise detraining on lipid storage in rats. Trans Ill St Acad Sci. 1999;92(3\&4):203-9.

32- Gomes F, Telo DF, Souza HP, Nicolau JC, Halpern A, Serrano CV Jr. Obesity andcoronary arterydisease: Role of vascular inflammation. Arq Bras Cardiol. 2010;94(2):255-61.

33- Taddei S, Galetta F, Virdis A, Ghiadoni L, Salvetti G, Franzoni $\mathrm{F}$, et al. Physicalactivity prevents age-related impairment innitric oxide availability in elderly athletes. Circ. 2000;101(25):2896-901.

34- Powers SK, Ji LL, Leeuwenburgh C. Exercisetraininginduced alterations in skeletal muscleantioxidant capacity: A brief review. Med Sci Sports Exerc. 1999;31(7):987-97.

35- Smith JK, Dykes R, Douglas JE, Krishnaswamy G, Berk S. Long-term exercise and atherogenic activity of blood mononuclear cells in persons at risk of developing ischemic heart disease. J Am Med Assoc. 1999;281(18):1722-7.
2011;16(4):154-61. [Persian]

3- Saghebjoo M, Ghanbari Niaki A, Rajabi H, Rahbarizadeh F, Hedayati M. The influence of circuit resistance training intensity on ghrelin to obestatin ratio of plasma in healthy young women. Iran J Endocrinol Metab. 2011;12(6):626-32. [Persian]

4- Hughes S. Novel cardiovascular risk factors. J Cardiovasc Nurs. 2003;18(2):131-8.

5- Herrmann W, Herrmann M, Obeid R. Hyperhomocysteinaemia: A critical review of old and new aspects. Curr Drug Metab. 2007;8(1):17-31.

6- Cannon RO. Role of nitric oxide in cardiovascular disease: Focus on the endothelium. Clin Chem. 1998;44(8 Pt 2):1809-19.

7- Zolfaghary M, Taghian F, Hedayati M. Comparing the effect of green tea extract consumption, aerobic exercise and combination of these two methods on CRP Level in obese women. Razi J Med Sci. 2013;20(110):8-21. [Persian]

8- Church TS, Barlow CE, Earnest CP, Kampert JB, Priest EL, Blair SN. Associations between cardiorespiratory fitness and C-reactive protein in men. Arterioscler Thromb Vasc Biol. 2002;22(11):1869-76.

9- Swift DL, Johannsen NM, Earnest CP, Blair SN, Church TS. Effect of exercise training modality on C-reactive protein in type 2 diabetes. Med Sci Sports Exerc. 2012;44(6):1028-34.

10- Senthil Kumaran V, Arulmathi K, Sundarapandiyan R, Kalaiselvi P. Attenuation of the inflammatory changes and lipid anomalies by epigallocatechin-3-gallate in hypercholesterolemic diet fed aged rats. Exp Gerontol. 2009;44(12):745-51.

11- Wang ZY, Das M, Bickers DR, Mukhtar H. Interaction of epicatechins derived from green tea with rat hepatic cytochrome P-450. Drug Metab Dispos. 1988;16(1):98103.

12- Yoshino K, Hara Y, Sano M, Tomita I. Antioxidative effects of black tea theaflavins and thearubigin on lipid peroxidation of rat liver homogenates induced by tertbutyl hydroperoxide. Biol Pharm Bull. 1994;17(1):146-9. 13- Muramatsu K, Fukuyo M, Hara Y. Effect of green tea catechins on plasma cholesterol level in cholesterol-fed rats. J Nutr Sci Vitaminol. 1986;32(6):613-22.

14- Kris-Etherton PM, Keen CL. Evidence that the antioxidant flavonoids in tea and cocoa are beneficial for cardiovascular health. Curr Opin Lipidol. 2002;13(1):419.

15- Maki T, Pham NM, Yoshida D, Yin G, Ohnaka K, Takayanagi $\mathrm{R}$, et al. The relationship of coffee and green tea consumption with high-sensitivity $\mathrm{C}$-reactive protein in Japanese men and women. Clin Chem Lab Med. 2010;48(6):849-54.

16- Eichenberger P, Mettler S, Arnold M, Colombani PC. No effects of three-week consumption of a green tea extract on time trial performance in endurance-trained men. I Int J Vitam Nutr Res. 2010;80(1):54-8.

17- Venables MC, Hulston CJ, Cox HR, Jeukendrup AE. Green tea extract ingestion, fat oxidation, and glucose tolerance in healthy humans. Am J Clin Nutr. 2008;87(3):778-84.

18- Buttar HS, Li T. Ravi N. Prevention of cardiovascular diseases: Role of exercise, dietary interventions, obesity and smoking cessation. Exp Clin Cardiol. 2005;10(4):229-49.

19- Kromhout D, Menotti A, Kesteloot H, Sans S. Prevention of coronary heart disease by diet and lifestyle: Evidence from prospective cross-cultural, 